\title{
Diagnostic assessment of an impact of static and dynamic vehicle loads on covering of roadway
}

\author{
Elena Kurakina $^{1 *}$, Sergej Evtyukov ${ }^{1}$, and Jaroslav Rajczyk ${ }^{2}$ \\ ${ }^{1}$ Saint Petersburg State University of Architecture and Civil Engineering, 190005 Saint Petersburg, \\ Russia \\ ${ }^{2}$ Czestochowa University of Technology, 42-201 Czestochowa, Poland
}

\begin{abstract}
The article presents diagnostic possibilities for testing covering of roadway through dynamic and static loading units. The article presents features, advantages and principal characteristics of the equipment: die unit, Dina-3M, UDN-NK, Dynatest unit. The main parameters of the dynamic impact units. The article also presents results of tests by dynamic and static loading, defines «flexural bowls», elastic module and the coefficients of reduction of the elastic modulus to the static modulus.
\end{abstract}

\section{Introduction}

Need of conducting diagnostic testing by determination of defects of road carpet, road deflections, modules of elasticity is caused by definition of residual resource of road carpet of the highway.

Existence of track, deflections of road carpet, change of its state in use promotes growth of accident rate. Periodic control and assessment of technical condition of the operated road carpets - indispensable condition for ensuring operating state and capacity of roads. Thereby the main objective - assessment of condition of road carpet and definition of residual life cycle of road carpet is caused.

\section{Material and methods}

One of the main factors of highway transport safety is the interaction of vehicles (V) with the highway surface. At present it is urgent to investigate the premature destruction of covering of roadway layers and its causes. During the operation covering of roadway undergoes transfigurations from the loads of moving vehicles, weather and climatic conditions, as a result of which a stress-strain state appears in it layers. By the time of exposure static loads have a longer period during which deformations reach their peak of development. The dynamic nature of the impact is short-lived, and the range of its intensity depends on transport-operational conditions (traffic intensity, vehicle class, axle loads, speed, and total vehicle mass) $[1,3,7,10-12]$. From the impact of vehicle traffic in covering of roadway appears vertical and horizontal stresses, decaying with depth due to the strength and material

*Corresponding author: elvl_86@mail.ru 
characteristics of the layers. All of this, as well as temperature effects, highway moistening and drying also cause stresses, tensile strains, shears, compression and torsion, which reduces the strength covering of roadway characteristics (Figure 1).

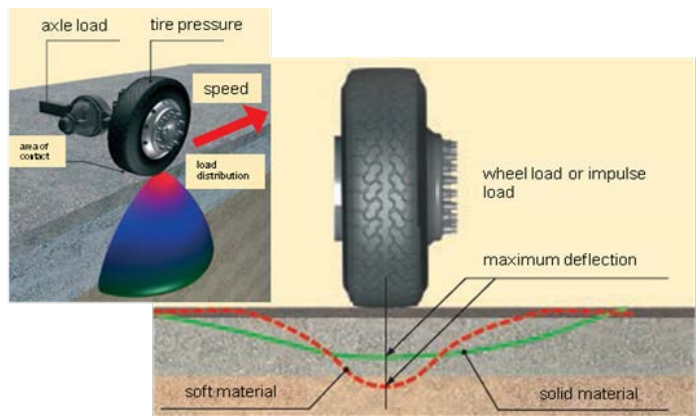

a)

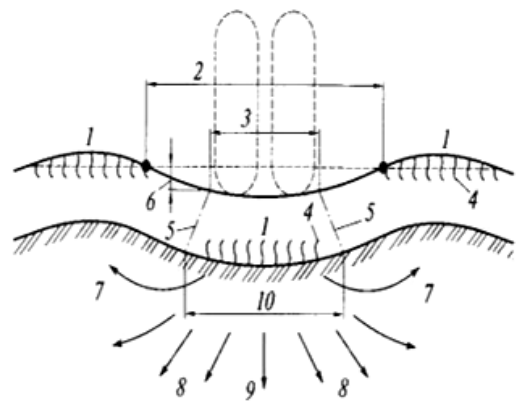

b)

a) "Flexural bowl" for rigid and non-rigid types of covering of roadway in 3D format; $b$ ) deformed state of covering of roadway: 1 - stretching zone; 2 - flexural bowl; 3 - zone of roadway compression;

4 - cracks in covering of roadway; 5 - cut surface of covering of roadway; 6 - covering of roadway deformation; 7 - the direction of the soil outburst; 8 - direction of soil compression; 9 - compaction of soil in the covering of roadway; 10 - ground pressure transmission area

Fig. 1. Impact of the car wheel on covering of roadway.

\section{Theory}

Strength characteristics of covering of roadway depends on the "flexural bowl", that is, the maximum allowable deflection value, as well as it depends on the amount of applied load during the period of weakening of covering of roadway $[2,4,5]$. During the operation of the highway, all deformations firstly proceed in a latent form, so it is difficult to recognize and anticipate their development. Thus, there is a need to monitor the parameters of the strength of covering of roadway.

Determination of covering of roadway strength is possible by using static and dynamic loading. The essence is to assess the covering of roadway bearing capacity and determine the index of the elasticity of general modulus. Stamp unit of static impact is a loading plate (metal disc) with a cylindrical support in the center and a load device with a hydraulic pump and a vehicle counterweight (figure 2).

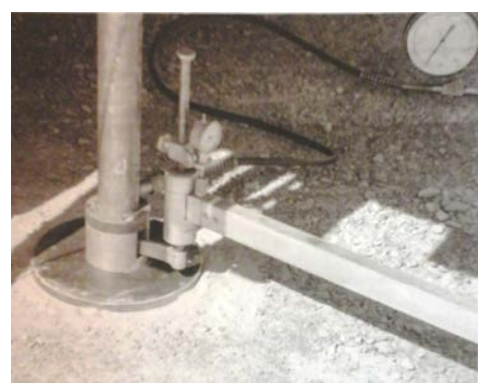

a)

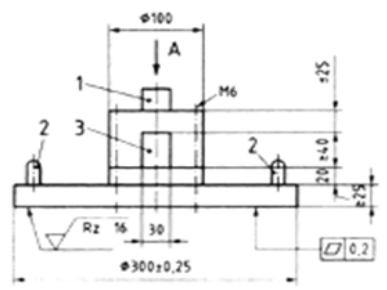

$\square 0.2$

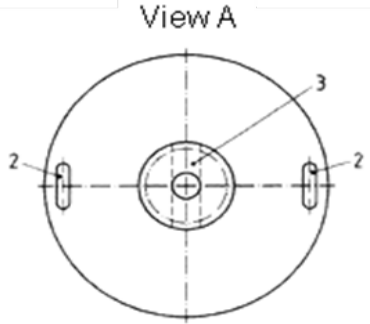

b)

a) general view; b) schematic diagram: 1 - centering pin with rotary head of hydraulic cylinder, 2 handle for plate transfer, 3 - tunnel for measurement, tolerance for measurements $+/-0,2 \mathrm{~mm}$

Fig. 2. Load plate for static testing. 
A special feature of the measurements is the obtaining of measurements by a stamping unit with the determination of the loading plate sedimentation depending on the applied or removed load, on which a graph is plotted (with polynomial curves of the general deformation in the case of primary loading, and unloading and elastic deformation under the secondary loading (ODM 218.5.007-2016 "Methodical recommendations for determining the modulus of elasticity by a static stamp ").

Dynamic loading units got an extensive use for estimating the modulus of elasticity (E). It can function as trailers to mobile laboratories or to other vehicles, they are operated in Finland, Denmark, Sweden and the USA. Holland, Sweden and Denmark use dynamic loading units of Phoenix and Kuab brands, also Russia use complex Dynatest. Test units of foreign practice such as Dynatest 8000 FWD (measurement by deflection analysis of weight deflected), 8000 VMD (deflectometer installs in a camper van or a minibus); 8081 HWD (measurement of elastic vibrations under the influence of a large weight load) satisfies the required conditions. The conditions: amplitude and duration of effort are identical to the impact of a heavy moving wheel load and high accuracy of deformation measurements $[1,2$, $4,6,11,12,13]$. General technical characteristics with the main components of the complex and the test results are shown in Figure 3.

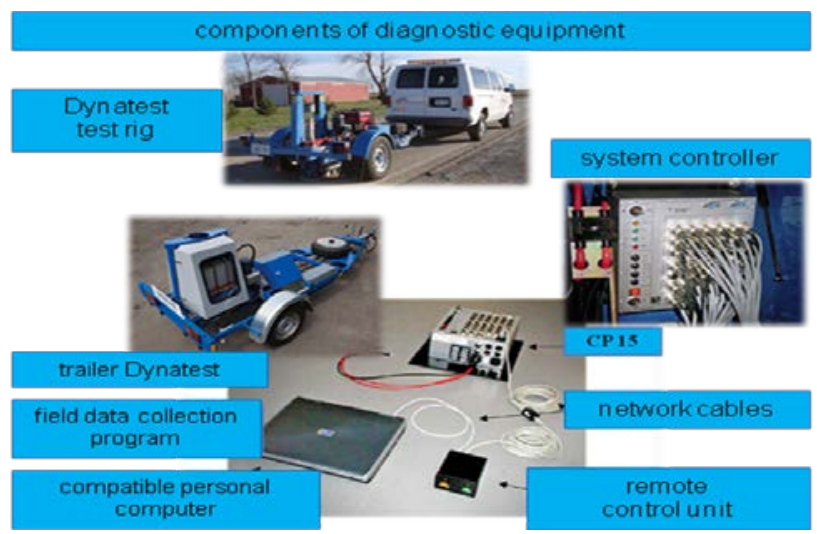

a)

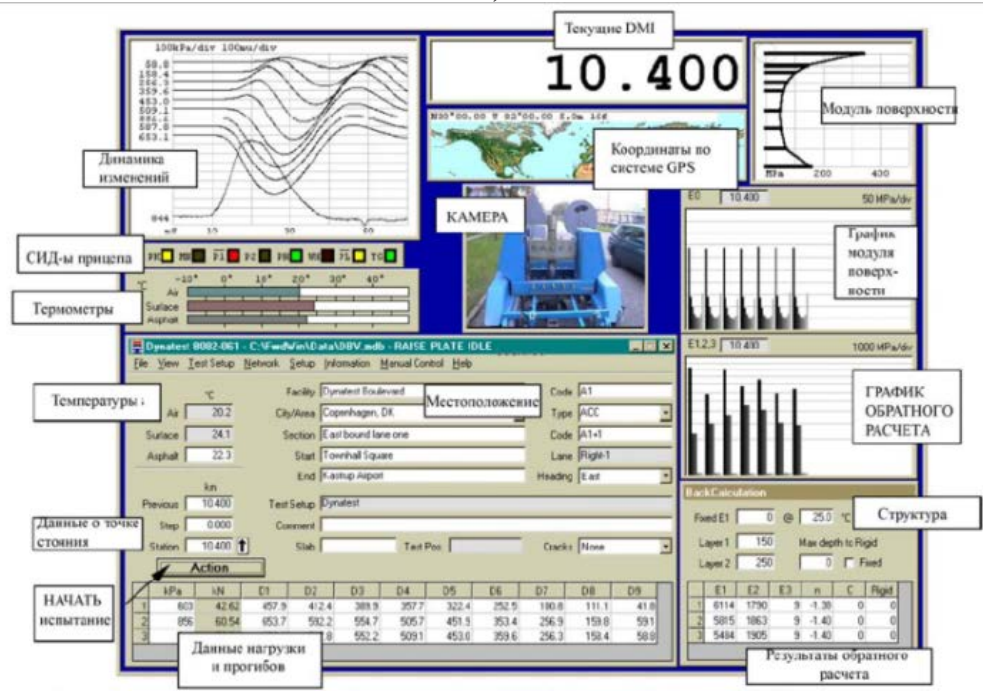

b)

Fig. 3. Dynatest dynamic loading unit. 
Using of automated measuring, analytical and control engineering support and equipment (deflectometer with software) on site allows determining the level of deformation caused by a controlled load with the highest accuracy, inaccessible to other existing methods. In Russian practice the diagnosis and assessment of highways state and the determination of the modulus of elasticity (E) were carried out by Dina-3M, UDN-NK (acting with dynamic loads) and the special instrument - a longspan lever-type deflectometer acting under static loading. Comparative characteristics of the dynamic impact unit's parameters are presented in Table 1.

Table 1. The main parameters of the dynamic impact units.

\begin{tabular}{|c|c|c|c|c|c|}
\hline $\begin{array}{c}\text { Type of } \\
\text { dynamic } \\
\text { impact units }\end{array}$ & $\begin{array}{c}\text { Height of load } \\
\text { drop, cm }\end{array}$ & $\begin{array}{c}\text { Load } \\
\text { weight, } \mathbf{k g}\end{array}$ & $\begin{array}{c}\text { Parameter } \\
\text { contact } \\
\text { interaction time, } \\
\text { s }\end{array}$ & $\begin{array}{c}\text { Diameter of } \\
\text { the stamp, } \\
\text { cm }\end{array}$ & $\begin{array}{c}\text { Pulse } \\
\text { impacts }\end{array}$ \\
\hline Dina-3M & 51 & 160 & 0,03 & 33 & sinusoidal \\
\hline UDK-3 & till 150 & 40 & 0,03 & 34 & Triangular \\
\hline Dynatest FWD & 45 & 235 & 0,03 & 33 & Half-Sinusoidal \\
\hline
\end{tabular}

An analysis of technical characteristics of the selected for comparison equipment made it possible to identify the possibility of determining the modulus of elasticity. The advantages of the Dynatest unit are the high accuracy of simulating the applied load on the covering of roadway from the moving vehicle wheel, and ability to determine for a short period of time the parameters: covering of roadway state; layerwise (and in layers) definition of a structure modulus of elasticity; the bearing capacity of covering of roadway and the expected residual life of the top layer; modeling of "weak" sections of roadways that affect the likelihood of road accidents.

\section{Results}

The main advantage of Dynatest dynamic impact unit is that during the correlation process the impact on the values of peak loads and elastic vibrations from possible undesirable components of high frequency in the load cycle can be minimized. The Dynatest unit monitors the temperature on the surface of roadway, in the upper layers and the surrounding environment $[4,8,9]$.

Tests using the dynamic and static loading method were carried out in the territory of St. Petersburg and the Leningrad Region, taking into account ODM 218.5.007-2016. "Methodical recommendations for determining the modulus of elasticity by static stamp".

The results of covering of roadway elastic deflection are presented in the form of a graph (Figure 4). Temperature during the testing in the upper layers of $19.8 \div 22.6^{\circ} \mathrm{C}$, on the surface of $20.7 \div 26.7^{\circ} \mathrm{C}$, air $18.8 \div 22.7^{\circ} \mathrm{C}$.

Simultaneous application of static and dynamic loading methods provides for presentation of results to the form according to ONE 218.1.052-2002 "Evaluation of the strength of non-rigid covering of roadways", MODN 2-2001 "Design of non-rigid covering of roadways:

$$
l_{f}=\left(X_{2} \cdot l_{D}\right)+X_{1},
$$

where $X_{1}$ and $X_{2}$ are the empirical coefficients of the regressional dependence; $l_{f}$ - the actual deflection of the structure at the distinctive section, corresponding to the permissible percentage of the deformed coating surface (design reliability of covering of roadway) under static loading by the design load; $l_{D}$ - the same that tested by setting a short-term unit. 


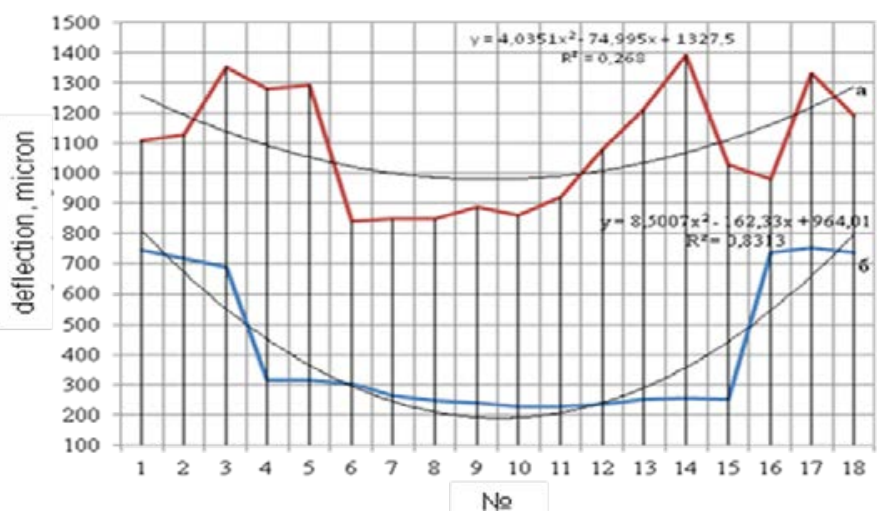

a) - deflection of covering of roadway under static load by a die unit; b) - deflection of covering of roadway under the dynamic load by Dynatest unit

Fig. 4. Tests results of dynamic and static loading.

Taking into account the formula 1 and the test results, we obtain the output data for determining the reduction coefficient of the elastic modulus (E) from the dynamic to static, at the same time taking into account ODM 218.3.072 - 2016 "Methodical recommendations for determining the remaining service life of non-rigid covering of roadway bearing capacity and elasticity modules of structural layers (Table 2).

Table 2. Reduction of the dynamic module to the static module.

\begin{tabular}{|c|c|c|c|}
\hline \multicolumn{2}{|c|}{ Total modulus of elasticity, Etotal, MPa } & \multirow{2}{*}{$\begin{array}{c}\text { Coefficient of } \\
\text { reduction of general } \\
\text { elastic moduli, } \mathrm{Xi}=\mathrm{Ed} \\
\text { / Est }\end{array}$} & \multirow{2}{*}{$\begin{array}{l}\text { root-mean- } \\
\text { square error }\end{array}$} \\
\hline $\begin{array}{l}\text { Dynamic modulus of } \\
\text { elasticity, Ed }\end{array}$ & $\begin{array}{l}\text { Modulus of elasticity } \\
\text { in static tests, Est }\end{array}$ & & \\
\hline \multicolumn{4}{|c|}{ Crushed stone, crushed stone-sandy layers } \\
\hline 206,6 & 261,0 & 0,79 & 0,0081 \\
\hline 216,3 & 246,0 & 0,88 & 0,0000 \\
\hline 210,5 & 213,0 & 0,98 & 0,01 \\
\hline \multicolumn{2}{|c|}{ Xсp } & 0,88 & \\
\hline \multicolumn{3}{|c|}{ Mean square deviation } & 0,06 \\
\hline \multicolumn{3}{|c|}{ Mean square deviation, $\%$} & 5,82 \\
\hline \multicolumn{4}{|c|}{ light-weight type, bituminous concrete } \\
\hline 501,3 & 327,0 & 1,53 & 0,0064 \\
\hline 500,5 & 336,0 & 1,49 & 0,0144 \\
\hline 522,3 & 365,0 & 1,43 & 0,0324 \\
\hline 535,8 & 266,0 & 2,01 & 1,96 \\
\hline \multicolumn{2}{|c|}{ Xmean } & 1,61 & \\
\hline \multicolumn{3}{|c|}{ Mean square deviation } & 1,14 \\
\hline \multicolumn{3}{|c|}{ Mean square deviation, $\%$} & 3,44 \\
\hline \multicolumn{4}{|c|}{ Fundamental type, bituminous concrete } \\
\hline 598,2 & 345,0 & 1,73 & 0,0031 \\
\hline 632,2 & 336,0 & 1,88 & 0,0084 \\
\hline 693,6 & 345,0 & 2,01 & 0,0486 \\
\hline 691,3 & 399,0 & 1,73 & 0,0033 \\
\hline 623,8 & 355,0 & 1,76 & 0,0011 \\
\hline 623,3 & 399,0 & 1,56 & 0,0518 \\
\hline 633,8 & 345,0 & 1,84 & 0,0022 \\
\hline \multicolumn{2}{|c|}{ Xmean } & 1,79 & \\
\hline \multicolumn{3}{|c|}{ Mean square deviation } & 0,13 \\
\hline \multicolumn{3}{|c|}{ Mean square deviation, $\%$} & 7,28 \\
\hline
\end{tabular}


The results of the calculations shows the ratio of dynamic modules to static ones as «1» on crushed stone and crushed stone-sandy layers; as «1,6» on light-weight asphalt-concrete cover and almost twice high on fundamental type of layers.

\section{Discussion}

The carried-out diagnostic assessment of impact of static and dynamic loads on road clothes allows to draw conclusion on relevance of use of the modern equipment which choice is proved by safety of carrying out technological measuring processes; convenience, speed of receiving and information processing; high possibility of the analysis of all range of the studied parameters.

By results of deflektometralny probe it is possible to define degree of risk of emergence of the road accidents, assessment of traffic safety and development of effective actions for drop of accident rate on "weak" sections of highways by means of assessment of deformation tension of constructive layers of road clothes, definition of the module of elasticity.

\section{Conclusion}

The diagnostic assessment of an impact of static and dynamic loads on covering of roadway allows us to conclude that the use of modern equipment is urgent, the choice of which is justified by the safety of conducting technological measurement processes; by convenience, by speed of receiving and processing information; by high possibility of analyzing the entire spectrum of the investigated parameters. When tested with static load the deflection is greater than with the dynamic one, because the static load degree of impact is longer in time. With short-term action of dynamic loads we obtain a larger value of the modulus of elasticity, which characterizes the ability to elastic deformation when applying loads.

\section{References}

1. S. Evtiukov, E. Kurakina, V. Lukinskiy, A. Ushakov, Methods of accident reconstruction and investigation given the parameters of vehicle condition and road environmen, Transportation Research Procedia, 20, Pages 185-192 (2017)

2. E.V. Kurakina, S. Evtyukov, Research of coupling characteristics of road covering at road accident autotechnical examination, Bulletin of Civil Engineers, 5 (52), P. 216$223(2015)$

3. E.V. Kurakina, A diagnostic study of road elements on the road accident sites with nondestructive testing, Bulletin of Civil Engineers, 6 (59). P.231-237 (2016)

4. Ulrich Brannolte, Pavel Pribyl, Valentin Silyanov, Simulation of Regional Mortality Rate in Road Accidents, Transportation Research Procedia, 20, Pages 112-124 (2017)

5. V.N. Dobromirov, S.S.Evtyukov, E.V. Kurakina, Improvements in the methods of road safety assessing on high-speed roads, The journal «Transport and Technological Cars», 1(56), P.94-101 (2017)

6. E.V. Kurakina, On the deviation of the normative characteristics of the highway indicators (on the example of the emergency-dangerous sections of the Leningrad Region roads, Modern problems of science and education, 2, (2014).

7. Ja. Rajczyk, M. Rajczyk, S Evtiukov, Dispersion of Kinetic Energy for Traffic Safety, Transportation Research Procedia, 20 (1), P. 536-534 (2017) 
8. V.N. Dobromirov, S.S. Evtyukov, report of research work "Scientific substantiation of the reconstruction process of traffic accidents by results of aerial photography", St. Petersburg, Russia, (2016).

9. S.A. Evtyukov, E.V. Kurakina, report of research work "Scientific and methodological support of a road and transport research by nondestructive method", St. Petersburg, Russia (2016).

10. S.A. Evtyukov, E.V. Kurakina, Improvement of the algorithm of auto technical expertise in the reconstruction of an car accident, taking into account the technical condition of the vehicle and the road, Materials of the 11th international conference "Organization and safety of traffic in large cities", P.518-527 (2014)

11. Targeted federal programme «Improving road safety in 2013-2020 years».

12. A Federal Traffic Safety Act of 10.12.1995 N 196-FZ (current version, 2016).

13. Pavel Pribyl, Alexander Novikov, Victoria Vasileva, Andrei Katunin, ITS Control of Highways Capacity, Transportation Research Procedia, 20, Pages 468-473 (2017) 